\title{
Library Support of Area Study Programs
}

\author{
By ROLLAND E. STEVENS
}

PARTICIPATION in two international wars and advancements in communication and transportation during the past halfcentury have made Americans increasingly aware of and curious about the rest of the world. In recent years the more remote and socio-economically underdeveloped countries have received most of this attention. Pioneering efforts have begun in colleges and universities in teaching the languages, political and economic development, and social and cultural characteristics of these nonwestern regions. While such efforts almost invariably reflect the interest of one or two members of the local faculty, the implementation and growth of these interests have been greatly fostered by support from the United States government and from educational foundations. Without this support, most of the programs centered on the relatively unknown parts of Asia and Africa would today still be one- or two-man efforts, supplemented by small uncataloged collections of books in the faculty offices.

The concept of area studies is a recent development in higher education. In an area program, the parts of various disciplines pertaining to a geographical area are studied together, in distinction from the traditional discipline-centered curriculum. Thus a class would study the languages and literature, the caste system, the political and economic history, art, music, religion, and culture of India. Area studies draw from disciplines in the humanities and social sciences, but exclude the natural sciences.

The support of area studies by the library gives rise to special problems. In the first place, library collections are
Dr. Stevens is Professor of Library Science in the University of Illinois.

classified by subject and only secondarily, if at all, by geographical area. Should the titles pertaining to the area under study be brought together, regardless of subject and regardless of language? Secondly, in the case of little-known languages, and most current area programs involve languages seldom taught in the United States until recently, there is the problem of finding staff with adequate language ability and with library training. Again, there are problems with regard to cataloging. What transliteration system, classification scheme, and filing rules should be adopted? Should cards in Arabic, Chinese, Hindi, Burmese be interfiled in the general card catalog? Finally, there are problems of acquisition. The book trade in underdeveloped areas is seldom as well organized as the book trade to which we are accustomed in Europe and America. In addition, problems of securing books and journals published behind the Iron and Bamboo Curtains must be solved.

The purpose of this article is to describe the practices of several research libraries in the eastern and midwestern United States with regard to area study programs. In 1962 and 1963 a faculty committee of the Ohio State University has been considering possible areas in which the university might profitably establish continuing study programs. Since the present resources and future needs of the library are acknowledged to be integral factors in the choice of areas for intensive study, the committee 
wanted a librarian to visit universities having strong area programs, in order to study the effects of such programs on the library. In January 1963 therefore the author visited the University of Michigan, University of Chicago, the University of Illinois, and Indiana University; in March, the University of Pennsylvania, Harvard University, Yale University, Columbia University, and Cornell University. The five areas that have been most developed at one or more of these institutions are Central and East Europe, East Asia, Southeast Asia, South Asia, and the Middle East. At each library information was sought about the size of area collections, their relation to the rest of the collection, their rate of growth, book and periodical budget, size and experience of staff, organization of staff, and general problems of acquisition and cataloging arising from the building of such special area collections. As yet, since the area program is a fairly recent phenomenon, there are no standard practices, no pat answers to the many problems encountered in building a supporting library collection. Not only has each library applied itself to the solution of its own problems and found solutions different from those tried in other universities, but even within a single library different patterns have been applied to the several area programs.

The number and seriousness of special problems imposed on the library by the area program are, with two exceptions, functions of the languages involved. Much of the problem of acquiring material from underdeveloped countries depends, of course, on the organization of the book trade and the availability of publications. The question of providing separate facilities for the area collection is as much a matter of the curriculum, of class assignments, and of the relative service to be afforded different student and faculty groups as it is a matter of the languages involved. But the integration of volumes in the general collection according to subject, the filing of cards in the general catalog, the acquisition of staff with requisite ability and training, the deployment of staff, and various problems of cataloging are clearly related to the languages involved. It can be readily understood that in an area program centered on Latin America, for example, the library should have little or no difficulty in finding bibliographers and catalogers familiar with Spanish and Portuguese, in revising the cataloging of materials in these languages, or in interfiling books and cards with those in other western languages. In a South Asia program, however, with materials written in Hindi, Urdu, Bengali, Marathi, and many other languages which are little known in the United States, these difficulties are intensified. Most area programs today are concerned with underdeveloped areas whose languages of publication are relatively unknown in this country.

\section{EAst Europe}

Each of the nine libraries visited has a strong program on East Europe. Harvard, with an estimated two hundred and fifty thousand volumes, and Columbia, with approximately two hundred thousand volumes, have the oldest and largest collections. Indiana (seventy thousand volumes), Michigan (sixty thousand volumes), and Illinois (sixty thousand volumes) have begun concentrated programs more recently. Most of the libraries have integrated their Slavic language holdings with books and periodicals in other languages according to subject. Several either have, or plan to have when additional space is available, a Slavic or East European reading room into which are collected the reference works and major sets pertaining to the area, along with current issues of newspapers and journals. The advantage of such a reading room is obvious in bringing together materials from various dis- 
ciplines which are studied simultaneously. The disadvantage is equally obvious in separating titles from the other works in the same subject field, either causing inconvenience to readers who concentrate on the discipline rather than the area, or requiring duplication of titles. With increasing knowledge of Slavic languages, particularly Russian, among scholars in various fields, the separation of books in these languages from other books is a growing inconvenience to nonarea specialists. Therefore the wholesale separation of books in Slavic languages is considered as unreasonable as would be the segregation of books in German or French. Yet a compromise may be achieved by setting up a reading room containing the most actively used books and journals on Slavic language and literature, history, government, sociology, and economics. Harvard has a working collection of 14,000 volumes in its Russian Research Center, outside the main library. All titles are duplicated in the main collection, and only those works needed in current research projects are kept in the Center. Books in this collection do not circulate.

An active program of selecting, acquiring, and cataloging books from East Europe requires a staff of from six to twelve persons, of whom about half are professional. One member of the staff is often designated to supervise the project; this is usually the person who has the major responsibility for selection. The supervisor maintains liaison with the teaching faculty and often teaches part time. He also generally decides on cataloging priorities, although the catalogers are administratively in the cata$\log$ department. Library school graduates who speak and read Russian, Polish, and other languages of East Europe are, if not plentiful, at least not as scarce as those required in some of the other area programs. Many are persons who have spent most of their lives in East
Europe but who went to library school in this country. A fair number, however, are Americans or West Europeans who have acquired a strong knowledge of the language either in the home or in school. In the majority of cases it is such a person who is designated as supervisor of the project, while staff members who have recently arrived from East Europe are assigned to bibliographic searching and cataloging.

Acquisition of material for an area program on East Europe is complicated by the difficulties of communicating freely and establishing sound business relations with dealers and libraries behind the Iron Curtain. Compounding the problem is a publishing industry geared primarily to domestic needs and providing only incidentally for the export trade. Except for propaganda intended for foreign consumption, most titles are printed in such small editions that it is necessary to check advance lists like Novye Knigi and order them before publication. Some of the libraries have placed blanket orders for all current publications of the USSR in designated subject fields. In these cases, Novye Knigi and other advance lists are still checked for titles which are not expected on the blanket order; these lists are then sent to the dealer with instructions to send if not supplied on blanket order. Other librarians feel strongly against blanket orders, believing that no amount of care and instruction to the dealer can prevent excessive receipt of unwanted publications. Whether or not the blanket order is used, regular checking of bibliographies of current publications and book review sections of newspapers and learned journals is necessary to a good acquisition program, particularly for publications of academies and other nontrade institutions and for the smaller republics of the USSR.

Acquisition of older publications (and here this means all publications more than two or three years old) is ex- 
tremely difficult. One of the richest sources of back titles and sets is the duplicate stock of several of the largest libraries in the USSR. Library duplicates, however, are not available by purchase, but only by exchange for desired western titles. Exchange with Russian libraries is not, as many an American librarian has learned, the relaxed matter to which he is accustomed. Specific titles are demanded by the Russian librarians, and a basis of exchange acceptable to both parties is not easily found. Some American librarians, not having university publications of sufficient quality or quantity to satisfy these stringent demands, purchase trade books and subscriptions to be sent to the Russian libraries for exchange. Most librarians in the nine institutions deplore the work and expense involved in such exchanges but nevertheless use them in order to get certain needed back publications. One (perhaps the only) bright spot in the acquisition of older publications is that no copyright restriction is recognized on Russian books; source publications, journals, and reference sets that are in demand and are not available in the original format are being reprinted or reproduced by Xerox and microform.

If staff having both library training and appropriate language ability are found, there are no cataloging difficulties peculiar to Slavic materials. Transliteration from Cyrillic alphabet is standard. Library of Congress cards are available for a high percentage of both older and current publications. Interfiling of cards with those in other languages presents no problem. Russian and, to a lesser degree, Polish, Czech, and the other Slavic languages are, in fact, next to the languages of West Europe in familiarity. At least one of the libraries visited, that of the University of Pennsylvania, assigns Slavic cataloging to three catalogers who also handle non-Slavic cataloging in their subject areas.

\section{East Asia}

The fascination of many centuries of Chinese civilization and the interest, particularly since 1946, in Japan have contributed to the establishment of several strong Asian collections. One of the largest in the country, and the largest of those visited, is the Chinese-Japanese Library of the Harvard-Yenching Institute. It was begun in 1927 and now contains about two hundred and seventy thousand volumes in the Chinese language, eightyseven thousand in Japanese, eleven thousand five hundred in Western languages, and a small number in Korean, Tibetan, Manchu, and Mongolian. Other outstanding collections are those at Columbia University (estimated two hundred and thirty-two thousand volumes), the University of Chicago (one hundred and forty-nine thousand volumes), Cornell University (one hundred and twenty thousand volumes, including material on Southeast as well as East Asia), Yale University (one hundred and one thousand volumes), and the University of Michigan (seventy-four thousand volumes). The statistical count of volumes, always hazardous, is especially doubtful when it includes Chinese books, which are traditionally bound in several parts, or $t s^{\prime} e$, to a volume. These large collections, except the one at Yale, are distinct from the library's general collection. Michigan, Chicago, and Cornell keep all books and periodicals in Chinese, Japanese, and other East Asian languages in a separate collection in the main library building. Harvard and Columbia have Asian collections in a separate building. A selected number of books and periodicals in Western languages pertaining to East Asia are also kept in these separate libraries. At Yale University books and periodicals in Chinese and Japanese are classified and shelved by subject with other books, except that "traditional" books (i.e., those published before 1850), and modern crit- 
icisms and books about these "traditional" books are classified as a group.

Unlike the staff working in a Slavic area program, the East Asian staff is composed almost wholly of Orientals. Only one or two occidental librarians are to be seen in the libraries visited, and these usually in circulation work. The staff is organized into two general groups: those who select or catalog Chinese materials, and those who select or catalog Japanese materials. Although the procedures followed in acquisition and cataloging are those followed throughout the library, and although in about one-half of the libraries the bibliographers and catalogers are members of the acquisition and catalog departments respectively, the East Asia programs are in general more independent of the library administration than are those on the other areas. At Michigan, Chicago, Harvard, and Columbia, the staff is under the direct supervision of the head of the East Asia program. Another respect in which the Asian staff differs from that of the Slavic program is in the library training of its members. While the majority have training in an American library school, each large staff has one or more members who received his training and/or experience in China or Japan, and these Asian librarians are usually senior members of the staff. As in other Asian area programs, competent library personnel is difficult to find. Japanese bibliographercatalogers are even more scarce than are their Chinese counterparts, probably because of the demand for trained librarians in Japan, as compared with the lack of opportunity in Taiwan.

Acquisition of Japanese material presents no particular difficulties. The book trade is well organized for export as well as for local needs. Governmental, academic, and other nontrade institutions are flattered to receive requests for their publications. Instead of driving a hard bargain for exchanges, these institutions are likely to respond generously to a polite and sincere request. None of the libraries has a blanket order for Japanese current publications; instead, dealers' lists of current and out-of-print books are checked regularly. National bibliographies, journals, and lists of academy and government publications are also examined for all titles of interest. American dealers in Japanese books are seldom or never used because of their relatively high prices. Getting books from mainland China is a different story. Most libraries maintain a standing order for current publications in designated subjects of the social sciences and humanities with one of the large Hong Kong dealers. Coverage of the significant mainland publications seems to be fairly satisfactory by this method. Several of the libraries also have exchange agreements with the National Library, Peking, but admit that receipts are not always complete. Acquisitions from Taiwan and South Korea are small but steady.

Chinese and Japanese, unlike many other languages, cannot be transliterated. The conversion of characters into roman letters is instead called "romanization." The Wade-Giles scheme of romanization has been adopted widely in this country for Chinese, as has the Hepburn system for Japanese. The cataloging done by the majority of the libraries follows closely the Library of Congress standard. It differs from cataloging of books in other languages most in the use of a different classification schedule and in the maintenance of unorthodox public catalogs. Although several of the libraries follow the same classification used for their general collections, Harvard, Yale, Chicago, Columbia, and Cornell employ a four-digit system devised by Dr. A. Kaiming Chiu, librarian of the Chinese-Japanese Library of the Harvard-Yenching Institute. The HarvardYenching Institute uses the Chiu classification for all of its Asian books; Chi- 
cago and Columbia, for their Chinese books; Yale, for Chinese and Japanese books published before 1850 and for modern critical works about these "traditional" books; Cornell, for Chinese books published before 1949. Those libraries having a separate collection of Asian materials have usually adapted their card catalogs to special needs of scholars using the collection. Instead of the usual dictionary catalog, most have a separate romanized author, or authortitle catalog for each language. Interfiling of author cards of books in the different languages would lead to unnecessary confusion to the reader. The subject catalog is usually a classified catalog in which the books in different languages are interfiled. The library of the Harvard-Yenching Institute, however, has for each of the three languages, Chinese, Japanese, and Korean, a separate romanized author catalog, a romanized title catalog, a subject catalog filed by Chiu classification, and a title catalog filed by the Wang "four corner" system. The Wang system of filing cards that are not romanized is familiar to Chinese and Japanese scholars. Chicago maintains a file of uncataloged Chinese books arranged by the K'ang-hsi key system. One of the filing difficulties encountered with romanized Chinese names is that the same romanization is used for different characters which are pronounced alike but in different tones. At Columbia, these similar names are distinguished by guide cards lettered with the romanized name followed by the appropriate Chinese character.

In general, it appears that the oldest and largest Asian libraries still preserve certain aspects of organization and methods familiar to Chinese and Japanese scholars. For example, in addition to romanized authors and titles, HarvardYenching and Chicago have catalogs in the characters of the original language; Columbia provides guide cards giving Chinese characters. Harvard-Yenching al- so gives titles in Chinese characters on the spines of books and periodicals bound in Cambridge. The newer collections, however, make fewer concessions to the Oriental scholar; or perhaps it is more exact to say that more concessions are made to the occidental scholar.

\section{SOUTHEast Asia}

This area, in which interest is much more recent and is evident in fewer libraries than interest in East Europe and East Asia, includes Thailand, Cambodia, Laos, Vietnam, Burma, Indonesia, and the Philippines. Only three of the libraries visited, Yale, Cornell, and Indiana, have significant Southeast Asia programs. Indiana and Yale shelve publications from the region by subject, regardless of language, and file cards in the general card catalog. Cornell shelves its Southeast Asian books with books from East Asia by subject. Cards are also filed in its public dictionary catalog, as well as in a reading room catalog. Finding staff members with the requisite language ability and with library training is quite difficult. In fact, the want of staff qualified in both respects has influenced librarians to employ persons having a good knowledge of the languages of the region, even though they have no library training. If the university has a library school, the staff member may supplement his in-service training with formal courses. Some revision of the cataloging done by nonprofessional staff can be done by professional catalogers who have little or no knowledge of the language.

Acquisition of materials from this area is more difficult than from any of the other areas studied. Two factors contribute most to this difficulty: the dearth of publication in the entire region, and the complete lack of an organized book trade. In certain countries of Southeast Asia, particularly Laos, north Vietnam, and Indonesia, these contributing factors are compounded by a third: government prohibitions against the exportation of books. In order to combat such obstacles, 
librarians have resorted to ingenious and imaginative methods. One librarian, having established close relations with libraries in Indonesia, purchases trade books and subscriptions in the United States requested by these libraries and exchanges them for Indonesian books which they have purchased for the exchange. In Burma a bookdealer sponsored by the local military government supplied Burmese publications successfully for a time, but this source has dried up recently. A Hong Kong dealer and a Paris dealer have been used but with little success for books from north Vietnam. If a librarian or a faculty member has a friend living in one of the Southeast Asian countries, this person is approached to act as an agent for regular procurement of local publications, either on the basis of a markup on individual books supplied or for a monthly fee. Exchange agreements are made when possible. Yale and Cornell have worked out a cooperative agreement by which Yale obtains and catalogs a duplicate copy of every Vietnamese publication it can obtain, and Cornell does the same for Thai publications. Because books are so difficult to obtain and because so few American libraries are acquiring them from this area, the library pursuing this area program usually seeks every local publication it can get and does not concern itself about getting duplicates or publications which are not of scholarly quality. Buying trips to the area by faculty or library members are important both in the immediate acquisition of books and especially in the establishment of continuing contacts. Even the librarians normally shunning the blanket order would be happy to set up such an arrangement for publications from Southeast Asia, if they could find a dealer or agent willing to supply materials on this basis.

Many of the books published in this area are in Dutch, French, or English. These give no particular difficulty in cataloging. The Tagalog, Indonesian, and Vietnamese languages are written in the roman alphabet. Transliteration of Thai is standard, but problems still exist in the adoption of uniform transliteration schemes for Burmese, Cambodian, and Laotian. For these languages, libraries have used transliteration that seems to be most reasonable, hoping that the future adoption of a different standard scheme will not force them to recatalog. Solution of this problem may be imminent, with the great current interest of the Library of Congress and of the Descriptive Cataloging Committee of RTSD's Cataloging and Classification section.

\section{South AsIa}

Collecting of current publications from India and Pakistan has received an impetus from the federal government's Public Law 480 project. This program uses foreign currencies owned by the United States, usually in underdeveloped countries, to obtain local publications having potential scientific or scholarly use and to catalog and send them to selected research libraries in this country. The Library of Congress, assisted by local staff in India and Pakistan, collects the publications. Each participating library contributes to the cost of centralized cataloging and receives sets of cards keyed to the publications. Although seven of the nine libraries participate in the Public Law 480 program for India and Pakistan, only two have significant area programs for Southeast Asia. The collection of the University of Chicago is estimated at fifteen thousand volumes in vernacular languages; that at the University of Pennsylvania is about twentyfive thousand volumes in vernacular and western languages. Both collections are housed separately from the main library buildings.

Staff with library training and the ability to read any of the approximately fifteen languages currently used in this area is quite difficult to find. Persons 
with language skill but without library training are pressed into service, often on a part-time basis. In-service training is provided by professional catalogers who know some Indic languages, and both universities are convenient to library schools.

The aim of the Public Law 480 program is to supply to each participating library a copy of every current publication of potential value to research or serious study. In their zeal the agents supply many books whose value to a particular library may be dubious, along with numerous works of clear value to scholarship. Each library must screen carefully its receipts, in order to decide which are worth preserving. This is, of course, professional work of the highest order. The actual checking in of books and matching books to catalog cards can be done by a clerk, since books, receipt lists, and catalog cards are keyed numerically. Acquisition of older publications from South Asia, although now overshadowed by the massive supplies of current publications, is necessary to most well developed area programs. The book trade of India, if not organized to the degree which we accept as normal, nevertheless does function fairly well. Lists and catalogs of dealers in Bombay, New Delhi, and other centers, are checked regularly for older publications which fit the program.

Except for the delay of about a year in receiving cards, the cataloging of current publications is greatly simplified by the centralized cataloging service of the Public Law 480 program. Books published before 1962, which are not included in the PL 480 plan, usually require original cataloging, creating the staffing difficulties discussed above.

\section{Middle EAsT}

The largest and most active programs on the Middle East among the nine libraries are those at Columbia and Har- vard. There are also programs at Michigan, Chicago, Indiana, and Pennsylvania. The collections at Chicago and Pennsylvania have grown out of an early interest in the languages and archaeology of the region. The others are of more recent date and are somewhat wider in scope. The Public Law 480 program collects current publications of the United Arab Republic, as well as from India and Pakistan, and all of the libraries mentioned above except Pennsylvania have elected to participate in this program. The acquisition of current publications from countries not in the UAR and of older publications from the area is extremely difficult. The problems are those already described for other areas: the scarcity of books, and the lack of an organized book trade. While lists from local bookdealers may be checked for current and older books of interest, the only satisfactory method of acquiring books (other than those supplied by PL 480) is to make periodic buying trips to the area. Such trips are valuable, not only for obtaining books but also for establishing and confirming good contacts with dealers, universities, and other academic and scholarly institutions. Blanket orders with local dealers are almost never satisfactory, since it is more or less traditional that the buyer not only pay personal visits to book vendors but also bargain at length when he finds a book of some use. Successful acquisition therefore requires not only an occasional trip to the area but the attention of a person well acquainted with local attitudes and psychology.

As in the two preceding area programs, finding staff with both library training and requisite knowledge of the languages is extremely difficult. Each of the libraries supporting a program in this area employs one or more persons who know the languages, although they lack library school degrees. When possible, such a staff member's in-service 
training is supplemented by courses in a nearby library school. Several of the librarians in charge of the Middle East or other area program have advanced degrees in the history of the area involved. This degree and its attendant knowledge may be considered as valuable as or even more important for the program than a library degree.

Except for the problem of finding staff with adequate knowledge of Persian, Turkish, or Arabic, the difficulties of cataloging are not great. Transliteration is standard, and cards with transliterated entries can be interfiled readily with cards in other languages. Harvard does not transliterate its cataloging entries; author-title files for each language in the vernacular alphabet are located adjacent to its general catalog. Subject cards for Arabic, Persian, and Old Turkish are interfiled in a separate card catalog. The PL 480 books from the UAR are cataloged cooperatively, with each participating library contributing to the cost. These cards are numerically keyed to the Arabic publications.

\section{Bibliographical Note}

No attempt is made here to give a complete list of readings on area programs. Anyone interested in pursuing the subject further, however, should be aware of the following basic books and titles. A good account of the development of area programs in American universities is given in Joseph Axelrod and Donald N. Bigelow, Resources for Language and Area Studies; a Report on an Inventory of the Language and Area Centers Supported by the National Defense Education Act of 1958 (Washington: American Council on Education, 1962), 96 pages. Another basic report of such programs is United States Bureau of Intelligence and Research, External Research Division, Language and Area Study Programs in American Universities (Washington: U.S. Department of
State, 1962), 143 pages. The Public Law 480 program is described by Robert $\mathrm{D}$. Stevens, "The Library of Congress Public Law 480 Programs," Library Resources and Technical Services, VII (Spring 1963), 176-88. Melville Ruggles and Vaclav Mostecky give important and detailed information about programs on East Europe in their Russian and East European Publications in the Libraries of the United States (New York: Columbia University Press, 1960), 396 pages. The six articles in Library $R e$ sources and Technical Services, Winter. 1963 , on area acquisitions contain much important information: Stanley West, "Acquisition of Library Materials from Latin America” (VII:7-12); Felix Reichmann, "Acquisition of Library Materials from Southeast Asia” (VII:13-21); Philip J. McNiff, "Acquisition of Library Materials from the Middle East" (VII:22-27); Warren Tsuneishi, "Acquisition of Library Materials from China, Japan and Korea" (VII:28-33); Dorothy B. Keller "Acquisition of Library Materials from East Europe" (VII:34-37); and Hans E. Panofsky, "Acquisition of Library Materials from Africa” (VII:3846). These papers were given at the meeting of the Acquisition section of the Resources and Technical Services Division held in Miami in June 1962. Another aid to acquisition is Philip J. McNiff, A List of Book Dealers in Underdeveloped Countries (Chicago: American Library Association, 1963), 44 pages. An important paper on selection and acquisition from Japan is Yukihisa Suzuki, "The Role of a Bibliographer in a Japanese Collection," College and Research Libraries, XXI (May 1960), 241-46. Further information on acquisition from Southeast Asia is given in Cecil Hobbs, Southeast Asia Publication Sources: an Account of a Field Trip, 1958-1959 (Ithaca, N.Y.: Cornell University, Southeast Asia Program, Dept. of Far Eastern Studies, 1960), 145 pages. 